$\xi=-1$

\title{
Social cultural factors influencing health seeking practices among men suffering from lower urinary tract symptoms attending surgical outpatient clinic at a county referral hospital in Kenya
}

\author{
Festus Mwendia Muriuki ${ }^{1}$ *, Bernard Wambua Mbithi ${ }^{2}$, Sherry Oluchina ${ }^{3}$ \\ ${ }^{1}$ Post graduate student school of nursing, Jomo Kenyatta University of Agriculture and Technology .Nairobi Kenya \\ ${ }^{2}$ Lecturer school of Nursing, Jomo Kenyatta University of Agriculture and Technology .Nairobi Kenya \\ ${ }^{3}$ Senior Lecturer School of Nursing, Jomo Kenyatta University of Agriculture and Technology Nairobi. Kenya \\ *Corresponding author E-mail: festusmwendia81@gmail.com
}

\begin{abstract}
Health seeking practices is critical towards early screening, detection and control of Lower Urinary Tract Symptoms (LUTS) whereby human prostate gland is the major cause of benign prostate hyperplasia (BPH) and prostate cancer (PCA), which mostly accounts for LUTS. Social cultural factors such as cultural beliefs, educational level, income level and religion among many others have a direct influence on health seeking practices both positively and negatively in as far as LUTS are concerned. The researcher explored social cultural factors influencing health seeking practices among men with LUTS attending surgical outpatient clinic at Meru level five hospital (Kenya). De-scriptive cross-sectional study design was used to collect data from 120 men with LUTS, and 4 health workers. Census method was used to select the study participants with questionnaires, interview guide and focused group discussion used as instruments of data collection. Quantitative data was analyzed using Statistical Package for Social Sciences (SPSS) software version 22, whereas the qualitative data was analyzed using qualitative techniques. Descriptive statistics were computed to generate percentages and frequencies, which were then presented in tables and charts. Logistic regression was used whereby P-values were employed to determine the statistical significance of results with cut off set at $(\mathrm{p} \leq 0.05)$. Majority $(67.0 \%)$ of the patients with LUTS were aged between 61-70 years. Also, majority $(68.8 \%)$ of the respondents had primary level of education, with majority $(72.0 \%)$ of them being farmers with an income level of below Ksh. 20,000. The study results showed that social cultural factors had statistical significant influence on health seeking practices among men with LUTS.
\end{abstract}

Keywords: Social Cultural Factors; Influencing; Health-seeking; Practices; Lower-Urinary-Tract-Symptoms.

\section{Introduction}

Lower urinary tract symptoms (LUTS) describe a distinct phenotype of a group of disorders affecting bladder and prostate that share common clinical manifestations to include frequency, urgency, nocturia, difficult in initiating urination, sense of incomplete bladder emptying, decreased force of stream and interrupted stream (Parsons 2010).The human prostate is the cause of Benign Prostate Hyperplasia(BPH) and Prostate Cancer (Pca) which mostly accounts for Lower urinary Tract Symptoms (Nehikhare et al., 2017). According to United states of America, Census Bureau International Data Base, it was projected that $1.9(45.2 \%)$ billion persons of the world population were affected by LUTS in 2008, and 2.3 billion (44.7\% of men) in 2018 will be affected ( Irwin et al 2011).

A study carried out concerning overlap of storage, voiding and post micturition symptoms and consequence for treatment seeking in United States of America(USA),United Kingdom (UK) and Sweden revealed that of the 14,139 men who participated in the study, 71\% of them testified as having at least one LUTS. In addition the study further revealed that a third of the subjects with LUTS had sought treatment (Sexton et al., 2009). Equally 1 out 4 men with LUTS/ BPH in Uganda spend money for transport to clinic due to LUTS/ bladder outflow obstruction (BOO) despite low economic resources (Stothers et al., 2017).

Men hold the belief that blood in urine and painful micturition are the warning signs to seek health care and this delays health seeking care. In addition, men belief that urinary symptoms especially dribbling and hesitancy are associated with ageing and that sexual changes are secretive and a taboo (Michelleking et al., 2017). Equally according to a study done in Nigeria (2016) on the preventive and treatment of LUTS, two thirds (72.1\%) of the subjects had complications of LUTS/BPH. This was because they presented themselves to the health care facility late. This was associated to poor health seeking behaviors, due to poor social economic status (Ugwumba etal 2014). In Kenya, the health sector through the National Reproductive Health Policy, 2007 and the National Reproductive Health Strategy, 20092015 provided the policy framework, with cancers of the reproductive organs being priority components (Ministry of Health [MOH], 
2010). Currently there are no documented studies that have been carried out at Meru Level Five county referral Hospital on socio-cultural factors influencing health seeking practices among men suffering from Lower Urinary Tract Symptom attending surgical outpatient clinic in the health care facility, hence the basis for this study.

\subsection{Aim of the study}

The aim of this study was to establish the social cultural factors influencing health seeking practices among men suffering from Lower Urinary Tract Symptom attending surgical outpatient clinic at Meru level five county referral hospital.

\subsection{Research question}

What are the social cultural factors that influence health seeking practices among men with LUTS attending surgical outpatient clinic at Meru level five county referral Hospital?

\section{Materials and method}

Cross-sectional design was used to conduct the study at Meru level five county referral hospital surgical outpatient clinic. The study population was 120 patients suffering from LUTS, 2 Physician and 2 nurses working at this clinic. The study included male patients who were above 40 years of age with LUTS since these symptoms start after 40 years of age. The study excluded patients who had mental illness or neurological diseases which affect bladder emptying. Patients with other chronic conditions like diabetes were also excluded. The study used the census method thus the sample size was 120 patients suffering from LUTS, 2 Physician and 2 nurses. Validity and reliability of data collection instruments was ensured.

Questionnaires were used to collect data from the respondents whereby the principal investigator and the research assistant read and interpreted the questionnaires to the respondents in a language they understood and filled appropriately for those who were not able to read and write. Administering the questionnaires was done after the patients had been attended to by the nurses and physicians at the clinic. Interview guide was used to collect data from key informants who included the physicians and nurses working at surgical outpatient LUTS clinic at the Meru level five county referral hospital. Key informants were interviewed when they were free and available. Focused group discussion was conducted on a clinic day to gather more information on social cultural factors that influence health seeking practices for LUTS, whereby a group of 8 patients who didn't participate in filling of the questionnaires were selected and the information collected inform of notes and recorders.

Qualitative and quantitative analysis techniques were used to analyze the data gathered. The responses were coded and entered for analysis using computer software Statistical Package for Social Sciences (SPSS) version 22. Descriptive analysis was used to analyze quantitative data to generate the mean, standard deviation and frequencies. On inferential analysis, logistic regressions were used whereby Pvalues were used to determine statistical significance of results with cut off set at $\mathrm{P} \leq 0.05$ ). The results were then presented using frequency distribution tables and charts. Qualitative data was analyzed using qualitative techniques mainly developing and applying codes, identifying themes, patterns and relationships and summarizing the data from direct quotes and selected comments from key informant interviews, and focused group discussion. This data was transcribed, coded and organized into themes, categories and patterns related to the study objectives and then reported in both descriptive and narrative.

Ethical clearance was obtained from respective ethical bodies and Meru teaching and referral hospital management .The researcher ensured that the respondents were informed of the research goals and objectives to minimize suspicion. Confidentiality was observed during the period of study by ensuring that their names didn't appear anywhere in the data collection tools. Informed consent was obtained from the respondents before data collection and the data stored in safe place.

\section{Results}

\subsection{Study subjects' social cultural factors}

Table 1: Respondents' sociocultural factors

\begin{tabular}{|c|c|c|}
\hline Factor & Frequency $(n=112)$ & Percentage \\
\hline \multicolumn{3}{|c|}{ Age Distribution } \\
\hline $40-50$ years & 3 & 2.7 \\
\hline $51-60$ years & 20 & 17.9 \\
\hline above 70 years & 14 & 12.5 \\
\hline \multicolumn{3}{|l|}{ Religion } \\
\hline Catholic & 72 & $64.3 \%$ \\
\hline Protestant & 29 & $25.9 \%$ \\
\hline Muslims & 6 & $5.4 \%$ \\
\hline Others & 3 & $4.4 \%$ \\
\hline \multicolumn{3}{|c|}{ Residents regions } \\
\hline Rural & 80 & $71.0 \%$ \\
\hline Urban & 32 & $29.0 \%$ \\
\hline \multicolumn{3}{|c|}{ Source of income } \\
\hline Farmer & 81 & $72.0 \%$ \\
\hline Casual work & 15 & $13 \%$ \\
\hline Business & 10 & $9 \%$ \\
\hline \multicolumn{3}{|l|}{ Marital status } \\
\hline Married & 99 & 88.4 \\
\hline Single & 2 & 1.8 \\
\hline Widowed & 8 & 7.1 \\
\hline separated & 3 & 2.7 \\
\hline
\end{tabular}




\begin{tabular}{|c|c|c|}
\hline \multicolumn{3}{|l|}{ Level of education } \\
\hline None & 7 & 6.3 \\
\hline Primary & 77 & 68.8 \\
\hline Secondary & 22 & 19.5 \\
\hline College & 5 & 4.5 \\
\hline University & 1 & 0.9 \\
\hline \multicolumn{3}{|l|}{ Income level } \\
\hline Below 20,000 & 87 & 77.7 \\
\hline $20,000-50,000$ & 19 & 17.0 \\
\hline \multicolumn{3}{|c|}{ Distance from residential region } \\
\hline Less than $2 \mathrm{Km}$ & 4 & 3.6 \\
\hline $2-5 \mathrm{Km}$ & 6 & 5.4 \\
\hline Above $5-10 \mathrm{Km}$ & 27 & 24.1 \\
\hline Above $10-15 \mathrm{Km}$ & 66 & 58.9 \\
\hline Above $15-20 \mathrm{Km}$ & 6 & 5.4 \\
\hline Above $20 \mathrm{Km}$ & 3 & 2.7 \\
\hline
\end{tabular}

Table (1) demonstrates the frequency and percentage of the social cultural factors among the respondents. The findings indicated that $3(2.7 \%)$ of the respondents were aged between 40-50 years, $20(17.9 \%)$ of them were aged between 51-60 years, 75(67.0\%) of the respondents were aged between $61-70$ years and 14(12.5\%) of the respondents were aged 70 years and above. On their religion, the study results showed that $72(64.3 \%)$ of the respondents were catholics, 29(25.9\%) of them were Protestants, 6(5.4\%) of them were Muslims, while $5(4.4 \%)$ of the respondents belonged to other religions. Regarding marital status, 99(88.4\%) of the respondents were married, $2(1.8 \%)$ of them were single, $8(7.1 \%)$ of them were widowed while $3(2.7 \%)$ of the respondents were separated.

The study results also showed that $32(29.0 \%)$ of the respondents lived in the urban areas while 80(71.0\%) of them lived in the rural areas. Among the respondents, $7(6.3 \%)$ of them had no formal education, $77(68.8 \%)$ of the respondents had primary level of education, $22(19.5 \%)$ of them had secondary level of education, $5(4.5 \%)$ of them had college level of education, while $1(0.9 \%)$ of the respondents had university level of education.

In terms of their sources of income, $6(6.0 \%)$ of the respondents were formerly employed, $10(9.0 \%)$ of them were earning their living through running various businesses, $15(13.0 \%)$ of them were causal laborers' while $81(72.0 \%)$ of them were farmers. Regarding the respondents' monthly income, the study showed that $87(77.7 \%)$ of them had an income below Kshs.20, 000, 19(17.0\%) of the respondents had their income ranging between Kshs. 20,000-50,000, 6(5.3\%) of them had their income ranging between Kshs. 50,000-100,000, while none of the respondents had an income level above Kshs. 100,000. In terms of residence, the study results showed that $3.6 \%$ of the respondents were living at a distance less than $2 \mathrm{~km}$ from the health care facility, $5.4 \%$ of them were living $2-5 \mathrm{~km}$ from the health care facility, $24.1 \%$ of them were living within $5-10 \mathrm{~km}$, with $58.9 \%$ of them living within $10-15 \mathrm{~km}$ from the health care facility. Among them, $5.4 \%$ of the respondents lived between $15-20 \mathrm{~km}$, whereas $2.7 \%$ of the respondents lived more than $20 \mathrm{~km}$ from their residence to the healthcare facility.

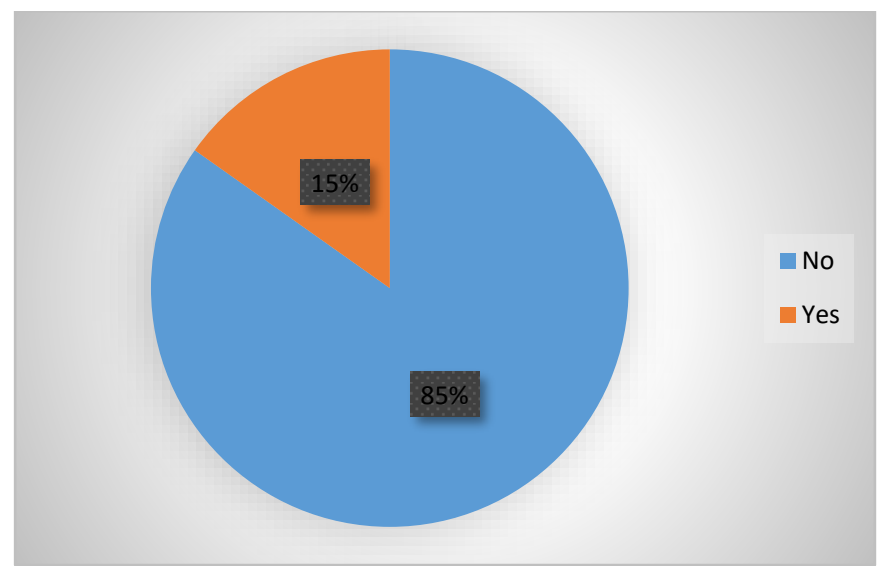

Fig. 1: Responses on whether the participants had cultural beliefs attached to health seeking practices

Figure (1) illustrates the percentage distribution on whether there were cultural beliefs attached to health seeking practices among men suffering from LUTS. Among the respondents, 95(85.0\%) of them said that there were no cultural beliefs attached to their health seeking practices whereas $17(15.0 \%)$ of them agreed that there were cultural beliefs attached to their health seeking practices in their community in regards to LUTS. Based on the analysis of the respondents' views regarding the cultural beliefs attached to health care seeking practices in their community among patients suffering from LUTS, the study findings showed that majority of respondents believed that men cannot undress in front of ladies even if these ladies were health care providers. The respondents also viewed sexual issues as taboos with some of them saying that LUTS are associated with normal ageing.

In terms of source of income, formal employment $(\mathrm{p}=0.001)$, being a casual $(0.003)$ and also being a farmer $(\mathrm{p}=0.002)$ had statistical significant influence on health seeking practices. However, being a business man $(\mathrm{p}=0.071)$ had no significant influence on health seeking practices. In terms of education, having primary level of education $(p=0.001)$, secondary level of education $(p=0.003)$, having college level of education $(\mathrm{p}=0.0001)$ and university education level $(\mathrm{p}=0.002)$ of education had a statistical significant influence on health seeking practices whereas those with no education $(\mathrm{p}=0.090)$ had no statistical significant influence on health seeking practices. The study findings also demonstrated that income level below Kshs 20,000 had a statistical significant influence on health seeking practices (pvalue $=0.002$ ) whereas an income of Ksh 20,000-50,000, Ksh 50,000-100,000, and above Ksh100,000 had no statistical significant influence on health seeking practices among the respondents $(\mathrm{p}=0.082,0.051$, and 0.078 respectively).

In terms of religion, being a Catholic $(\mathrm{p}=0.003)$ or a protestant $(\mathrm{p}=0.001)$ had a statistical significant influence on health seeking practices among men with LUTS. However, being a Muslim $(\mathrm{p}=0.065)$, having traditional beliefs $(\mathrm{p}=0.079)$ and belonging to other religions 
$(\mathrm{p}=0.117)$ had no a statistical significant influence on health seeking practices among the respondents. The study results also showed that being married $(\mathrm{p}=0.001)$, widowed $(\mathrm{p}=0.003)$ and also having separated $(\mathrm{p}=0.002)$ had a statistical significant influence on health seeking practices among the respondents. On the other hand, being single $(\mathrm{p}=0.071)$ or being divorced $(\mathrm{p}=0.053)$ had no significant influence on health seeking practices.

It was also evident from the study findings that areas of residence, both in urban and rural had a statistical significant influence on health seeking practices $(\mathrm{p}=0.0001$ and $\mathrm{p}=0.022$ respectively). Likewise, living less than $2 \mathrm{~km}(\mathrm{p}=0.077)$ or within $2 \mathrm{~km}-5 \mathrm{~km}(\mathrm{p}=0.063)$ from the health care facility had no statistical significant influence on health seeking practices among the respondents while living within 5-10km $(0.004), 10-15 \mathrm{~km}(\mathrm{p}=0.002), 15-20 \mathrm{~km}(0.001)$ or more than $20 \mathrm{~km}(\mathrm{p}=0.0001)$ from the health care facility had a statistical significant influence on health seeking practices among the respondents.

\section{Discussion}

This study provides an opportunity to better understand the social cultural factors influencing health seeking practices amon $g$ men suffering from LUTS. The study revealed that majority (67.0\%) of the study subjects were aged between $61-70$ years which was similar to study done by Abdkadir et al 2016 on open prostatectomy in the management of benign prostate hyperplasia in a developing economy country which showed that majority of the patients were aged between 61-70 years. On marital status $88.4 \%$ were married with only $1.8 \%$ of them being single. Regarding religion majority were Christians, mainly Catholics (64.3\%) and Protestants (25.9\%). On education status majority $(68.8 \%)$ of study the subjects had primary level of education, while $6.3 \%$ had no formal education .Concerning occupation majority $(72.0 \%)$ were farmers with only $6 \%$ of them being in formal employment. All these findings are consistent with the ones in a study conducted by Ojewola et al (2017) on knowledge, attitude and screening practices regarding prostatic diseases among men older than 40years in Nigeria which revealed that majority $(88.2 \%)$ of the participants were married while the remaining $11.8 \%$ were either single, divorced or widowers and that majority $(84.3 \%)$ of them were christians, with $79 \%$ of the participants having primary level of education. The study further indicated that majority $(31.1 \%)$ of the participants were farmers, $24.3 \%$ were in formal employment while $20.0 \%$ of them were casual labourers. On income levels the study revealed that majority $(77.7 \%)$ of study subjects earned below Kshs.20, 000 monthly which is almost similar to study done by Dotson et al (2016) about epidemiology of prostate cancer in Jamaica whereby majority of respondents lived below 53 USD weekly.

In this study $85.0 \%$ of the respondents said that there were no cultural beliefs attached to their health seeking practices in regards to LUTS. Based on the analysis of the respondents' views regarding whether cultural beliefs are attached to health care seeking practices in the community on LUTS, the study findings showed that majority of respondents belief that men cannot undress in front of ladies even if these ladies are health care providers. The respondents also viewed sexual issues as taboos with some of them saying that LUTS are associated with normal ageing. This was in agreement with study conducted by Michelleking et al (2017) which revealed that, men belief that urinary tract symptoms are associated with ageing and that sexual changes are secretive and a taboo. Further this was in consistency with study done on barriers to medical help-seeking practices among older men with prostate cancer which showed that negative attitude towards help seeking behaviors was related to male gender role, fear of the health condition, medical and treatment procedures and embarrassment as a consequence of medical examinations and communication with health and non-health professionals to include disclosure of sexual-related symptoms (Perucha et al (2017).

Social cultural factors that influenced health seeking practices among men suffering from LUTS attending surgical outpatient clinic included employment, where by formal employment $(\mathrm{p}=0.001)$, being a casual $(0.003)$ and also being a farmer $(\mathrm{p}=0.002)$ had statistical significant influence on health seeking practices. However, being a business man $(p=0.071)$ had no significant influence on health seeking practices. In terms of education, having primary level of education $(p=0.001)$, secondary level of education $(p=0.003)$, having college level of education $(\mathrm{p}=0.0001)$ and university education level $(\mathrm{p}=0.002)$ had a statistical significant influence on health seeking practices whereas those with no education $(\mathrm{p}=0.090)$ had no statistical significant influence on health seeking practices. This showed that for the men who had no formal education, they had poor health seeking practices. This was in agreement with a study conducted in Nigeria by Ojewola et al (2016) on lower urinary tract symptoms prevalence, perception and healthcare-seeking behavior amongst Nigerian men, which revealed that the healthcare-seeking behavior of the respondents increased with increasing educational status and that respondents with a tertiary education had visited a hospital to complain about their symptoms, while more than one-third of respondents without any formal education had not sought help for their condition. Not surprisingly, educational status was found to be a significant factor that determined the healthcare-seeking behavior.

The study findings also demonstrated that income level below Kshs 20,000 had a statistical significant influence on health seeking practices (p-value $=0.002$ ) whereas an income of Ksh 20,000-50,000, Ksh 50,000-100,000, and above Ksh100,000 had no statistical significant influence on health seeking practices among the respondents ( $p=0.082,0.051$, and 0.078 respectively). However, contrary to these findings, a study conducted by Prajsner et al., (2014) on the social economic profile of elderly polish men treated for BPH indicated that men receiving pharmacotherapy for BPH were more likely to have been employed in the formal sector, lived in cities and also had a higher level of income. Concerning religion, the study showed that being a Catholic $(p=0.003)$ or a protestant $(p=0.001)$ had a statistical significant influence on health seeking practices among men with LUTS. However, being a Muslim ( $\mathrm{p}=0.065)$, having traditional beliefs $(\mathrm{p}=0.079)$ and belonging to other religions $(\mathrm{p}=0.117)$ had no a statistical significant influence on health seeking practices among the respondents. The results of this study disagreed with the findings of a study by Ojewola et al (2017) in Nigeria which revealed that religion had no influence $(p=0.685)$ on health seeking behaviors for LUTS. The study also showed that being married ( $p=0.001)$, widowed $(\mathrm{p}=0.003)$ and also having separated $(\mathrm{p}=0.002)$ had a statistical significant influence on health seeking practices among the respondents. On the other hand, being single $(\mathrm{p}=0.071)$ or being divorced $(\mathrm{p}=0.053)$ had no significant influence on health seeking practices. This was in line with study carried out by Jung et al (2017) on social-demographic factors related to lower urinary tract symptom in men, which revealed that marital status and family structure had an impact on access to care for LUTS and were correlated with a greater likelihood of patients neglecting their symptoms. In particular, some patients who had low income levels, were separated or divorced, or who resided within a nonmultigenerational family structure did not necessarily seek medical care, even with severe LUTS, perhaps due to the relative weakness of such family structures. This may be exacerbated by the possibility that such a family structure may be accompanied by having a lower income or being separated or divorced.

On areas of residence, living in both urban and rural areas had a statistical significant influence on health seeking practices ( $\mathrm{p}=0.0001$ and $\mathrm{p}=0.022$ respectively). This was different from study done in china by Zhang et al (2018) where by the prevalence of LUTS was 1.5 higher in urban than rural areas. Distance from residential area to health facility had influence on health seeking practices where by distance less than $2 \mathrm{~km}$ had $(\mathrm{p}=0.077)$ or within $2 \mathrm{~km}-5 \mathrm{~km}(\mathrm{p}=0.063)$ from the health care facility had no statistical significant influence on 
health seeking practices among the respondents while living within $5-10 \mathrm{~km}(0.004), 10-15 \mathrm{~km}(\mathrm{p}=0.002), 15-20 \mathrm{~km}(0.001)$ or more than $20 \mathrm{~km}(\mathrm{p}=0.0001)$ from the health care facility had a statistical significant influence on health seeking practices among the respondents. This could probably be due to the fact that when one resides away from the health care facility, he has to set aside some budget in order to seek health care services.

Therefore the researcher rejected the null hypothesis that "there is no significant relationship between social cultural factors and health seeking practices among Men with LUTS at the Meru level five county referral hospital" and accepted the alternative hypothesis that "There is a significant relationship between social cultural factors and health seeking practices among Men with LUTS at the Meru level five county referral hospital".

\section{Conclusion and recommendation}

\subsection{Conclusion}

Based on the findings of the study it can be concluded that social cultural factors had a statistical significant influence on the health seeking practices among men with LUTS attending surgical outpatient clinic at Meru Level Five Hospital. The researcher concluded that various social cultural factors such as residential proximity to the hospitals, income level, occupation and level of education influences the health seeking behavior among men with LUTS.

\subsection{Recommendations}

1) The government through the ministry of health should adopt measures of educating and promoting awareness among its citizens on the need for regular screening/testing and treatment for LUTS.

2) The government should develop guidelines on screening/testing for LUTS and ensure they are followed to the later

3) The government should ensure that those health care providers in the peripheral facilities are well trained, sensitized and conversant with these guidelines.

\section{Acknowledgement}

I thank my family for the moral and emotional support they accorded me during the entire process of this study

\section{References}

[1] Parsons J. K (2010). Benign prostatic hyperplasia and male lower urinary tract symptoms: Epidemiology and risk factors. Current bladder dysfunc tion reports 5(4):212-218. Cross Ref. https://doi.org/10.1007/s11884-010-0067-2.

[2] Nehikhare,O.,Kasivisvanathan,V.,Ellis,H.,Challacombe,B.(2017) Anatomy, physiology $\quad$ of larg Prostate.In:Kasivisvanathan.V.,ChallacombeB.(eds). The Big Prostate Springer, Cham. ; 27(5):2095-2109 https://doi.org/10.1007/s00330-016-4479-z.

[3] Irwin,D.,Kopp,Z.,Agatape,B.,Milson,I. \& Abram,P.( 2011).Worldwide prevalence of lower urinary tract symptoms, overactive bladder, urinary incontinence and bladder outlet obstruction BJU International, 108:1132-1139 https://doi.org/10.1111/j.1464-410X.2010.09993.x.

[4] Sexton,C.,Coyne,K.,Koop,Z.,Irwin,D.,Milson,I.,,Aiever,L., (...)Wein,A. (2009).The overlap of storage, voiding and post micturition symptoms and implications for treatment seeking in USA,UK and Sweden. British Journal of Urology International 103(3):12-23. https://doi.org/10.1111/j.1464410X.2009.08369.X.

[5] Stothers L,Adrew J,Francis B,Sharif M \& Jonathan B (2017).Association between the severity of obstructive lower urinary tract symptoms and care seeking behavior in rural Africa ,Uganda Public Library of Science France, 12(3): https://doi.org/10.1371/journal.pone.0173631.

[6] Michellekinng,,Arber,A.\& Faithfull ,S.(2017). Routes to diagnosis for men with prostate cancer: men's cultural beliefs about how changes to their bodies and symptoms influence help-seeking actions. European Journal of Oncology Nursing 30(1):48-58 https://doi.org/10.1016/j.ejon.2017.06.005.

[7] Ogwumba F,Ozoema O,Okoh A,Echetaba K,\& Mbadiwe O (2014).Transvesical prostatectomy in the management of benign prostatic hyperplasia in a developing country. Nigeria journal of clinical practice 17(6). https://doi.org/10.4103/1119-3077.144402.

[8] Ministry of Health.(2010) National Reproductive Health Strategy 2009-2015.https://www.k4health.org.

[9] Abdukkadir A.,Tajudeen A.,Afolabi M,Rotimi A,Chinedu U,Chigozie I (2016) Open prostatectomy in the management of benign prostate hyperplasia in a developing economy . https://doi.org/10.4236/oju.2016.612029.

[10] Ojewola R, Ezekiel O, Olanrewaju B, Ezra O, Taiwo A ${ }^{1}$, Oluseyi B,(...), Rotimi O,(2017) Knowledge, attitudes and screening practices regarding prostatic diseases among men older than 40 years: a population-based study in Southwest Nigeria. The Pan African Medical Journal. 2017; 27:151. https://doi.org/10.11604/pamj.2017.27.151.10605.

[11] Dotson S, MD Howard M, Aung M, Keenan J, Jolly P The epidemiology of prostate cancer in western Jamaica: Risk factors, knowledge, attitudes and practices. The West Indian medical journal · May 2015. https://doi.org/10.7727/wimj.2014.183.

[12] Perucha,L.,Yousaf,O.,Hunter,M.\& Grunfeld,E.(2017).Barriers to medical help-seeking among old men with prostate cancer. Journal of Psychosocial Oncology 35(5):531-543. https://doi.org/10.1080/07347332.2017.1312661.

[13] Ojewola W,Ezekiel S,Olanrewaju S,Ezra O \& Taiwo A (2016).Lower urinary tract symptoms: prevalence perceptions and health care seeking behavior amongst Nigerian men. African journal online.World J Mens Health.34 (3):200-208. https://doi.org/10.5534/wjmh.2016.34.3.200.

[14] Prasner A,Chudek J,Szybalska A,Piotrowicz K,Zejda J \& Wiecek A (2014).Social economic profile of elderly polish men treated for benign prostate hyperplasia. European Geriatric Medicine 6(1):53-57. https://doi.org/10.1016/j.eurger.2014.08.004

[15] Jung K.,Kyu K.,Ji N.,Bo C.,Hong M (2017) Social demographic factors related to lower urinary symptoms in men. A Korean community health survey. International neurourology journal.21 (2):143-151 https://doi.org/10.5213/inj.1732760.380.

[16] Zhang W, Zhang X, Li H,Wu F, Wang H, Zhao M, Hu H, Xu K,(2018) Prevalence of lower urinary tract symptoms suggestive of benign prostatic hyperplasia (LUTS/BPH) in China: results from the China health and retirement longitudinal study.BMJ Open2019;9:022792. https://doi.org/10.1136/bmjopen-2018-022792. 